\title{
O DIREITO FUNDAMENTAL AO ENSINO NA CONSTITUIÇÃO FEDERAL: OS LIMITES APRESENTADOS PELO ARTIGO 208 DA CONSTITUIÇÃO FEDERAL DE 1988 AO ENSINO SUPERIOR PÚBLICO
}

Recebido: 18.03 .2020

\author{
Yara Maria Pereira Gurgel \\ Pós Doutora pela Faculdade de Direito da \\ Universidade de Lisboa. Doutora pela PUC/SP. \\ Professora da UFRN. \\ E-MAIL: ygurgel@uol.com.br \\ LATTES: http:/ / lattes.cnpq.br/8686260157736966 \\ ORCID: https:/ / orcid.org/0000-0003-4012-9995
}

\author{
Aprovado: 15.03.2020
}

\author{
João Fabrício Dantas Jr \\ Mestrando em Direito na UFRN. Pós-Graduado \\ pela Universidade Anhanguera. \\ EMAIL: fabriciodantas1305@gmail.com \\ LATTES: http:/ /lattes.cnpq.br/4172333716816646 \\ ORCID: http://orcid.org/0000-0001-6012-4775
}

\begin{abstract}
RESUMO: O ensino superior público no Brasil, segundo a Constituição Federal de 1988, apresentou-se como algo não alcançável por todos, devido as limitações intelectuais impostas pela literalidade do Artigo 208 do referido documento. Assim, se num primeiro momento não alcança um status de direito fundamental, ao contrário de níveis inferiores de ensino, alcançados pelo caput do Artigo $6^{\circ}$, esse mesmo ensino superior público passa a receber, também por permissão constitucional, efeitos de tratados internacionais pertinentes ao tema ensino superior como um direito social -, que, mesmo ainda refratário - direito que abrangeria apenas alguns grupos -, levanta a possibilidade da análise acerca do status constitucional do ensino superior público. Quais seriam as características do fornecimento do ensino superior público que o fariam se portar como um direito, o status desse direito, sua adequação ao serviço público, e ainda como tratados internacionais influenciariam em sua natureza jurídica, que poderia vir a alcançar um direito verdadeiramente social, de todos? A Convenção Internacional sobre os Direitos das Pessoas com Deficiência e seu Protocolo Facultativo tornam-se um marco nacional para os alcances do direito em tela alonguem-se. Contudo, a saber qual a abrangência dessa evolução dará, sim, também a qualidade de seu status.
\end{abstract}

PALAVRAS-CHAVE: direito humano; ensino superior; deficientes;

ABSTRACT: Public higher education in Brazil, according to the Federal Constitution of 1988, presented itself as something that cannot be reached by all, due to the intellectual limitations imposed by the literality of Article 208 of the referred document. Thus, if at first it does not reach a fundamental right status, in contrast to lower levels of education, achieved by the caput of Article 6, that same public higher education starts to receive, also by constitutional permission, effects of international treaties pertinent to the theme - higher education as a social right -, which, even though still refractory - a right that would cover only a few groups , raises the possibility of analyzing the constitutional status of public higher education. What would be the features of the provision of public higher education that would make it behave as a right, the status of that right, its suitability for public service, and how international treaties would influence its legal nature, which could come to achieve a truly social right, of all? The Convention on the Rights of Persons with Disabilities and its Optional Protocol become a national framework for the scope of the law in question to be extended. However, knowing the scope of this evolution will, yes, also give you the quality of your status as a right.

KEYWORDS: human right; higher education; disable people. 
SUMÁRIO: 1 Introdução 2 Natureza jurídica do ensino superior 2.1 A formação científica superor pública e o serviço público 2.2 A formação científica superior pública e o concurso público $3 \mathrm{O}$ direito subjetivo e o pleito jurisdicional à vaga em uma universidade pública $4 \mathrm{Os}$ limites dos limites ao direito social constitucional do ensino - o caso do ensino superior e seu requisito intelectual 5 Cotas em Universidades Publicas 6 O direito internacional dos direitos humanos e seus reflexos no brasil acerca do direito ao ensino superior público 7 Conclusão 8 Referências

\section{Introdução}

O ensino público brasileiro, um direito previsto na Constituição Federal de 1988, é um reflexo e um sinal das lutas políticas que antecederam a promulgação da própria Constituição. 0 direito social ao ensino público é dado pelo Texto, já no caput do seu Artigo $6^{\circ 1}$. O Artigo $208^{2}$ do mesmo texto, em seu inciso $V$, revela-nos que, no que refere-se ao ensino superior, este, por sua vez, será publicamente concedido a apenas aqueles que demonstrem capacidade para tal. Assim, é seguro dizer que a Constituição Federal, limitando-se, nos entrega que, sendo um ensino um direito social, ele encontra limites quando estivermos diante do ensino superior.

O ensino superior seria um direito humano? Seria um direito fundamental? Ou apenas uma previsão específica presente no texto constitucional que não poderia encontrar guarida na abertura do rol daqueles primeiros, sendo apenas uma obrigação constitucional estatal que não se revestir-se-ia daquela qualidade?

O (direito ao) ensino superior apresenta-se como um meio de melhoria de vida para uma grande parte da população brasileira, é certo. Décadas atrás carregava caráter extraordinário na sociedade brasileira; pouco mais de um século atrás era privilégio apenas daqueles cujas famílias pudessem enviá-los à Europa. Esses motivos sociais, que correm para a ciência do Direito, não nos permitem abandonar a interpretação científica do texto constitucional, que não poderá, nunca, ser lido apenas por algumas de suas partes, como afirmou Eros Roberto $\operatorname{Grau}^{3}(2009)$ :

Acompanho o voto entendendo, contudo, ser outra a fundamentação da afirmação de inconstitucionalidade das interpretações judiciais que autorizaram a importação de pneus. Isso de um lado porque recuso a utilização da ponderação entre princípios para a decisão da questão de que se cuida nestes autos. De outro porque, tal como me parece, essa decisão há de ser definida desde a interpretação da totalidade constitucional, do todo que a Constituição é. Desse último aspecto tenho tratado, reiteradamente, em textos acadêmicos. Não se interpreta $o$ direito em tiras; não se interpreta textos normativos isoladamente, mas sim o direito, no seu todo --- marcado, na dicção de Ascarelli, pelas suas premissas implícitas. (GRAU, 2009)

1 BRASIL. Constituição Federal de 1988. Retirado do sítio de Internet <http://www.planalto.gov.br/ccivil 03/constituicao/constituicao.htm>, com consulta em 20 de Janeiro de 2020.

2 Ibidem: V - acesso aos níveis mais elevados do ensino, da pesquisa e da criação artística, segundo a capacidade de cada um;

3 SUPREMO TRIBUNAL FEDERAL. Dizeres repetidos por Eros Roberto Grau, ministro aposentado do Supremo Tribunal Federal, tanto em publicações acadêmicas quanto em votos. Numa das oportunidades, observada no julgamento da Arguição de Descumprimento de Preceito Fundamental 101, em seu voto-vista, retirado do sitio de Internet <http://www.stf.jus.br/arquivo/cms/noticiaNoticiaStf/anexo/ADPF101ER.pdf>, em $1 \mathrm{de}$ Abril de 2019.

26 | Revista do Programa de Pós-Graduação em Direito da UFBA, e-issn 2358-4777, v. 30, n. 01, p.25-39, Jan-Jun 2020 
Assim, uma decisão política fundamental presente na Constituição Federal, e o ensino superior, de acordo com o Artigo 208 da Constituição, em seu inciso V, torna-se acessível apenas a aqueles que demonstrem capacidade.

A definição jurídica, essa um entendimento necessário quando se analisa textos positivos ou doutrinários que introduzem institutos jurídicos, e ainda o alcance de um direito, quando esse texto consubstancia-se de uma prestação estatal, devem ser aprofundados no Brasil quando lidamos com o acesso ao ensino superior. Até que ponto o investimento público, majoritariamente federal para o corte acadêmico, em entidades de ensino e no ensino propriamente dito, teria que abarcar, além da qualidade, essa dada pelo próprio Artigo 37 da Constituição Federal, pois uma prestação pública, também a quantidade, na medida em que mais e mais brasileiros buscam graduar-se superiormente?

\section{Natureza Jurídica do Ensino Superior Público}

Como todo estudo de um instituto jurídico, é sempre salutar buscar reflexões acadêmicas que nos apresentem sua classificação, no caso, sua natureza jurídica.

\subsection{A Formação Científica Superior Pública e o Serviço Público}

Observado que a educação é um direito social previsto na Constituição, direito este limitado pela própria Constituição quanto à meritocracia intelectual, concluímos que o ensino superior público não se trata, certamente, de um direito humano. Tampouco poderia ser definido como um direito social, ao contrário da educação fundamental e da educação média quando publicamente oferecidas.

Poderia o ensino superior público, oferecido majoritariamente pela União Federal, ser considerado um serviço público? Certamente é resultado do exercício legal de competências dadas às autarquias federais especiais - personalidade jurídica adotada pela ampla maioria das universidades públicas. Para este nível de educação em específico, o constituinte originário decidiu guardar escolhidos, termo usado por Jorge Reis Novais(2006, pg. 63) ${ }^{4}$ exatamente para distinguir o que não seria uma das características dos direitos humanos:

3. Em qualquer dessas instâncias, a ideia dos direitos como trunfos, se adequadamente compreendida e aplicada, desempenha um papel de relevo quando os juízes recorrem à metodologia da ponderação de bens, seja para determinarem, em primeiro lugar, a eventual prevalência do interesse pretensamente justificador da restrição do direito fundamental, seja para verificarem a constitucionalidade da concreta medida restritiva.

a) como se disse, a igual dignidade de todos determina que a opinião e as visões de mundo da maioria tenham para o Estado de Direito valor igual ao das opiniões e concepções de um só cidadão ou de uma minoria. Logo, a maioria não se pode fazer prevalecer da força do número para calar a voz da minoria ou para lhe impor visões, concepções e formas e planos de vida alheios; se está em causa a restrição de direitos fundamentais como efeito necessário da prossecução do interesse público, não é o argumento maioritário, mas unicamente argumento de razão pública que podem fundamentar a

4 NOVAIS, Jorge Reis. Direitos Fundamentais: Trunfos Contra a Maioria. Coimbra: Coimbra Editora, 2006.

27 | Revista do Programa de Pós-Graduação em Direito da UFBA, e-issn 2358-4777, v. 30, n. 01, p.25-39, Jan-Jun 2020 
cedência do direito. A maioria política pode decidir a limitação de direitos fundamentais, mas essa intenção vai estar sujeita ao escrutínio da justiça constitucional, a quem cabe verificar se pretendida cedência do direito se deve ao peso específico que representa, face ao direito fundamental, o interesse justificador da restrição (cuja prevalência deve, enquanto tal, ser fundamental em razões de razoabilidade e de justiça compartilháveis por qualquer pessoa razoável e não apenas por aqueles que perfilhem uma dada concepção particular do bem ou da vida virtuosa, isto é, a concepção de bem dos titulares do poder) ou se o que está em causa é, no fundo, a tentativa de sacrifício de liberdade individual ao fim de imposição dessa particular mundividência a toda a sociedade. (grifo nosso). (NOVAIS, 2006)

Se algum serviço ou mesmo direito for concedido pelo Poder Público mediante pagamento, prova de capacidade intelectual ou alguma distinção que venha a separar pessoas por suas características diferenciadoras, não estaremos diante de um direito humano ${ }^{5}$. Por conseguinte, certamente não estaremos diante de um direito fundamental, presente no texto constitucional.

O ensino superior público ofertado por universidades, sempre mediante processo seletivo qualificatório pela intelectualidade necessária a escolher aqueles melhores posicionados dentro do número de alunos que, administrativa e legalmente, se decidiu trabalhar por semestre para o curso oferecido, não é, certamente, para todos. O serviço público poderia delimitar aqueles que, preenchendo determinados requisitos, tanto objetivos quanto possíveis - no caso, provas de conhecimento acadêmico-, venham a receber determinado provimento público de um serviço específico ou especializado, seja geográfica, etária, intelectual ou, ainda, qualquer outro parâmetro que forneça a diferenciação pública necessária?

Di Pietro(2014; pg. 107) ${ }^{6}$ nos traz algumas considerações sobre os traços que definem o serviço público, na qual este sempre carregará a necessidade coletiva e pública como um de seus objetivos. Não cabe, para o serviço público, auferir capacidades técnicas, intelectuais ou ainda financeiras de seus usuários. Assim, as universidades públicas não fornecem serviço público propriamente dito, pois se assim fosse, haveria de ser amplo, isonômico e inclusivo.

\subsection{A Formação Científica Superior Pública e o Concurso Público}

Não sendo um direito fundamental, pois guarda, certamente, escolhidos; não sendo um serviço público, pois esse serviço não adota o caráter universal da prestação do serviço público

5 Cf. GURGEL. Yara Maria Pereira. Conteúdo Normativo da Dignidade da Pessoa Humana e suas Implicações Jurídicas na Realização dos Direitos Fundamentais. Tese de Pós-Doutoramento em Direito e Ciênicas Jurídicas. Lisboa. 2018: Pg. 82:A análise dos casos abrangendo direitos fundamentais demonstra que o STF Brasileiro faz uso do instituto da dignidade da pessoa humana como valor fundamental e princípio estruturante da ordem normativa nacional. Isso se dá na mais variada esfera temática de direitos fundamentais, quase sempre impondo limites ao Estado (quanto às liberdades fundamentais) e também assegurando o cumprimento do dever-ser como atuação necessária à implementação dos direitos prestacionais (ex. educação e saúde).

6 PIETRO, Maria Sylvia Zanella di. Direito Administrativo. Vigésima Sétima Edição, São Paulo-SP: Editora Atlas S.A. 2014: Daí a nossa definição de serviço público como toda atividade material que a lei atribui ao Estado para que a exerça diretamente ou por meio de seus delegados, com o objetivo de satisfazer concretamente às necessidades coletivas, sob regime jurídico total ou parcialmente público. 
conforme a lei, a oferta pública do ensino superior, no Brasil, seguindo os parâmetros científicos adotados por entendimento majoritário da doutrina Direito Constitucional acerca dos direitos fundamentais, e ainda também aquele entendimento majoritário da doutrina do Direito Administrativo acerca do serviço público, resta, diante dos procedimentos de provas aplicados pelo Exame Nacional do Ensino Médio ou ainda por vestibulares adotados anteriormente pelas universidades públicas, admitir que o ensino superior público é prestação pública fornecida a aqueles que se submetam ao concurso público.

Concurso Público não confunde-se com o serviço público - referindo-se a sua prestação, e não o acesso aos seus quadros funcionais por brasileiros - ou, mais ainda, com os direitos fundamentais e os direitos sociais presentes na Constituição Federal.

Diante de uma prestação pública que fugirá, por permissão constitucional, daquilo constitucionalmente imposto para a generalidade do ensino público, para todas as pessoas jurídicas de Direito Público na República, inclusive para a União, ou seja, a universalidade do serviço, o ensino superior, conformando-se em parte a um serviço público prestado para cumprimento de um dever estatal, limita-se onde o serviço público não pode ser limitado - sua universalidade para usufruto de todos -, carregando consigo processo seletivo para que apenas aqueles mais capacitados possam cursar um estudo de nível superior estatalmente provido.

A isonomia constitucional, que transborda-se também para o Direito Administrativo, mostra-se o fundamento para que o ensino básico e intermediário seja um direito fundamental. Todos, indistintamente, possuem o direito a exigir o provimento deste serviço público. Contudo, no ensino superior, a isonomia constitucional, que por limitação igualmente constitucional, é afastada em parte. Pela isonomia constitucional ${ }^{7}$, diante de um ensino superior que mostra-se seletivo, por sua capacidade intelectual, tanto para a seleção de entrada, como para a caminhada no curso e a sua conclusão, temos que ela dar-se-á apenas para o concurso público promovido pela instituição de ensino público especificamente, ou ainda pelo conjunto delas, organizado pelo Instituto Nacional de Estudos e Pesquisas Educacionais Anísio Teixeira - INEP-, através do Exame Nacional do Ensino Médio - ENEM, um direito a que todos, cumprindo os requisitos mínimos exigidos, objetivos, participem do certame que poderá dar acesso ao ensino em tela.

Assim, definindo a natureza jurídica do acesso ao ensino superior público, nesse ponto do desenvolvimento lógico-científico de um instituto jurídico, facilitar-se-á o desenrolar de todas as conclusões lógicas sobre ele, visto que poderíamos nos perder em erros diante de faces que, reconhecemos, poderiam mostrar o ensino superior público como um direito fundamental ou, ainda, como um direito social, ambos de índole constitucional. Aqueles primeiros fundamentos, a depender de qual a definição da dignidade da pessoa humana venha a se adotar, um dos fundamentos da República ${ }^{8}$, a própria dignidade da pessoa humana. 0 ensino superior, é claro, pelas escolhas constitucionais, não se encontra entre os direitos fundamentais, e, assim,

7 Cf. CARVALHO, Matheus. Manual de Direito Administrativo. 2a Ed, São Paulo-SP: Editora Jus Podivm, 2015. Pg. 88: A isonomia justifica, portanto, o estabelecimento de garantias a determinados grupos socialmente prejudicados, como forma de diminuir as desigualdades em relação ao restante da coletividade, sendo a base para a criação de ações afirmativas, que visam a inclusão na sociedade de pessoas menos favorecidas, por algum motivo. Por exemplo, neste sentido, a legislação cria a obrigatoriedade de se estabelecer um número de vagas em concursos públicos destinadas aos portadores de deficiência. Neste sentido, 0 art. $5^{\circ}$, $\S 2^{\circ}$, da lei 8.112/90 dispõe que "Às pessoas portadoras de deficiência é assegurado o direito de se inscrever em concurso público para provimento de cargo cujas atribuições sejam compatíveis com a deficiência de que são portadoras; para tais pessoas serão reservadas até $20 \%$ (vinte por cento) das vagas oferecidas no concurso".

8 BRASIL. Constituição Federal. Art. 1․ Retirado do sítio de Internet <http://www.planalto. gov.br/ccivil_03/constituicao/constituicao.htm>, com consulta em 20 de Janeiro de 2020.

29 | Revista do Programa de Pós-Graduação em Direito da UFBA, e-issn 2358-4777, v. 30, n. 01, p.25-39, Jan-Jun 2020 
também não se encontra dentre os direitos que comporiam o conteúdo mínimo da dignidade da pessoa humana. Como serviço público, não cumpriria a universalidade da prestação.

Como concurso público, não poderíamos cair no erro designativo em adotar essa modalidade de seleção apenas para o provimento de cargos ou funções públicas, conforme a lei 8.112 de 1990. Concurso público é todo aquele procedimento público para que trate isonomicamente aqueles que não puderem ser tratados diferentemente, e, portanto, concurso público é técnica para o convívio de particulares com o Poder Público, seja para contratar, para assumir cargos públicos ou, ainda, para matricular-se em instituições de ensino públicas superiores, sempre, em todos os casos acima listas, para a seleção daqueles melhores capacitados. O mesmo procedimento imposto pela Constituição Federal é seguido pela Lei das Licitações Públicas da União, a lei 8.666 de 1993, que trata das licitações e dos contratos administrativos, e na qual encontramos a modalidade concurso, não confundida com o concurso para o provimento de cargos públicos. Contudo, não estamos diante de licitações e contratos públicos, mas sim diante do cumprimento de um dever estatal, constitucionalmente previsto, a cargo majoritariamente da União, e que por decisão igualmente constitucional através de provas para a seleção dos melhores, pois a quantidade não é objetivo a ser atingido pelo ensino público superior estatal, ao contrário do ensino fundamental e intermediário, mas sim a excelência, pois constitucionalmente definido assim - os níveis mais altos de ensino, apenas e somente apenas, pela capacidade de cada um, algo desnecessário para os direitos humanos e fundamentais e ainda para usufruir os produtos da prestação de serviços públicos.

\section{Direito Subjetivo e o Pleito Jurisdicional à Vaga em uma Universidade Pública}

O pleito às vagas em creches públicas ${ }^{9}$ e ainda em escolas públicas de nível fundamental e intermediário é uma constante em noticiários e pesquisas jurisdicionais. Tema já decidido junto ao Supremo Tribunal Federal. Não pode haver falha pública no sentido da universalidade

9 SUPREMO TRIBUNAL FEDERAL. RE 956.475/2016. Relatoria do Ministro Celso de Melo. Retirado do sítio de Internet <http://www. stf.jus.br/arquivo/cms/noticiaNoticiaStf/anexo/RE956475RJDeciso.pdf>, com consulta em 24 de Janeiro de 2020: Tenho para mim, desse modo, presente tal contexto, que os Municípios - que atuarão prioritariamente no ensino fundamental e na educação infantil (CF, art. 211, § 2o) - não poderão demitir-se do mandato constitucional, juridicamente vinculante, que lhes foi outorgado pelo art. 208, IV , da Constituição, e que representa fator de limitação da discricionariedade político-administrativa dos entes municipais, cujas opções, tratando-se de atendimento das crianças em creche e na pré-escola (CF, art. 208, IV), não podem ser exercidas de modo a comprometer, com apoio em juízo de simples conveniência ou de mera oportunidade, a eficácia desse direito básico de índole social.

$[\ldots]$

Isso significa, portanto, considerada a indiscutível primazia reconhecida aos direitos da criança e do adolescente (ANA MARIA MOREIRA MARCHESAN, "O princípio da prioridade absoluta aos direitos da criança e do adolescente e a discricionariedade administrativa", "in" RT 749/82-103), que a ineficiência administrativa, o descaso governamental com direitos básicos do cidadão, a incapacidade de gerir os recursos públicos, a incompetência na adequada implementação da programação orçamentária em tema de educação pública, a falta de visão política na justa percepção, pelo administrador, do enorme significado social de que se reveste a educação infantil, a inoperância funcional dos gestores públicos na concretização das imposições constitucionais estabelecidas em favor das pessoas carentes não podem nem devem representar obstáculos à execução, pelo Poder Público, notadamente pelo Município (CF, art. 211, § 20), da norma inscrita no art. 208, IV, da Constituição da República, que traduz e impõe, ao Estado, um dever inafastável, sob pena de a ilegitimidade dessa inaceitável omissão governamental importar em grave vulneração a um direito fundamental da cidadania e que é, no contexto que ora se examina, o direito à educação, cuja amplitude conceitual abrange, na globalidade de seu alcance, o fornecimento de creches públicas e de ensino pré-primário "às crianças até 5 (cinco) anos de idade" (CF, art. 208, IV, na redação dada pela EC no 53/2006).

30 | Revista do Programa de Pós-Graduação em Direito da UFBA, e-issn 2358-4777, v. 30, n. 01, p.25-39, Jan-Jun 2020 
do oferecimento deste direito, a não prover o número de vagas necessárias a todos aqueles que pretendam se ver matriculados em instituições públicas para tanto - visto ser a lógica do direito social previsto na Constituição, de acordo com a limitação igualmente constitucional quanto ao ensino superior público. Há, nesse sentido, um direito líquido e certo, capaz de ser defendido através de mandado de segurança para que sejam forçados os poderes públicos competentes para tal e destinar destacamento orçamentário e a implementação administrativa, geralmente acompanhado de prazo em liminar para tanto, a que sejam oferecidas vagas em creches, escolas primárias e ainda secundárias no município onde haja a falta.

Para o ensino superior público, um pensamento diferente. Aqui, não cabe a defesa de um direito enquanto não houver prova de que há adequação intelectual de acordo com o que fora planejado, legalmente, para a oferta do ensino nesse nível, por seleções que definirão a entrada, o curso e, por fim, e concessão formal desta qualificação. Fernandes(2017, p. 732$733)^{10}$, contudo, vê que a educação pública superior estaria contida no direito à liberdade da escolha de profissão:

Importante lembrar, também, que o direito à educação não se encontra restrito ao universo do ensino fundamental, alcançando também o ensino superior. Falar em proteção constitucional à liberdade de escolha profissional (art. $5^{\circ}, \mathrm{XIII}$ ) é, indiretamente, compreender que cabe ao Estado promover prestações para a efetivação do direito ao ensino superior. Aqui é interessante citarmos decisão nesse sentido, proferida pelo Tribunal Constitucional Alemão, em que foi acolhida essa tese, de modo que o ensino superior é direito pressuposto para o livre exercício de uma profissão, marcando aqui a tese de direitos e prestações implícitas no texto constitucional alemão.

Respeitosamente, algo com o que não concordamos. A liberdade é conferida constitucionalmente sobre a escolha, e não sobre sua formação, esta passível de seleção, conforme o mesmo texto constitucional. A liberdade de profissão, assim, não garantiria a capacidade intelectual de ser aprovado numa seleção de um curso superior numa universidade pública, como, por exemplo, não garantiria a beleza da voz para aqueles que almejarem ser cantores, ou a habilidade com os pés para outros que desejarem ser jogadores profissionais de futebol. Mesmo para profissões, há necessidades e requisitos objetivos e subjetivos, legais e administrativos, veladores da isonomia constitucional, diante da educação superior pública. Se essa profissão necessitar, por lei, formação de nível acadêmico superior, então a escolha pessoal não será suficiente, e na seara pública essa pessoa deverá provar-se que encontra-se entre os melhores, por disposição igualmente constitucional, conforme o inciso $\mathrm{V}$ do Artigo 208 do mesmo documento, supra. Não cabe formação educacional por simples desejos, alegando direito, já que o direito fundamental é dado sobre a escolha, e não sobre a formação concedida. Há condições ${ }^{11}$, igualmente constitucionais, para a formação profissional, como os requisitos acadêmicos, se esses forem exigidos.

Não caberia, assim, direito a ser exigido judicialmente para o ingresso nas vagas ofertadas por universidades públicas sem a aprovação em vestibulares ou no Exame Nacional do

10 FERNANDES, Bernardo Gonçalves. Curso de Direito Constitucional. 9a Edição, São Paulo-SP: Editora Jus Podivm. 2017.

11 BRASIL. Constituição Federal de 1988. Retirado do sítio de Internet <http://www.planalto.gov.br/ccivil_03/ constituicao/constituicao.htm>, com consulta em 24 de Janeiro de 2020.

XIII - é livre o exercício de qualquer trabalho, ofício ou profissão, atendidas as qualificações profissionais que a lei estabelecer;

31 | Revista do Programa de Pós-Graduação em Direito da UFBA, e-issn 2358-4777, v. 30, n. 01, p.25-39, Jan-Jun 2020 
Ensino Médio, afora caso de erros em correção de provas que configurassem violação do direito à isonomia do tratamento público entre aqueles que concorressem em igualdade de condições.

\section{Os Limites Dos Limites ao Direito Social Constitucional do Ensino - O Caso do Ensino Superior e seu Requisito Intelectual}

Como dito, o ensino público no Brasil é um direito social. Contudo, a própria Constituição Federal limita-se - e limita-o-, ao dizer que sobre esse específico direito, há gradações. Podemos concluir, seguindo à risca a literalidade do texto constitucional, que o direito - social - à educação refere-se a aquela educação que abarcaria o nível básico e o intermediário. A primeira a cargo, majoritariamente, dos municípios; a segunda, dos Estados, quando, logicamente, estivermos diante de seu caráter público. O ensino superior público restaria à União oferece-la, preponderantemente. Tudo conforme a Constituição Federal e a Lei de Diretrizes e Bases da Educação Nacional ${ }^{12}$. Contudo o direito social ao ensino público superior, afora a todas as limitações que poderiam debruçar-se sobre sua concretização e sobre sua legitimação, como orçamento, competência, diretrizes, ainda carrega, para si, o limite intelectual.

Não cabe, aqui, dúvidas positivas sobre a meritocracia e a capacidade intelectual como requisitos para aqueles que pretendam ingressar nas vagas públicas do ensino superior, visto ser essa uma decisão do Poder Constituinte originário, segundo $\operatorname{Branco}\left(2009\right.$, pg. 232) ${ }^{13}$, uma certeza jurídica e uma liberdade política para tanto, por características do próprio Poder Constituinte:

Essas noções sobre o poder constituinte originário chegam até nós e inspiram os atributos que se colam a esse ente. Dizem os autores que se trata de um poder que tem na insubordinação a qualquer outro a sua própria natureza; dele se diz ser absolutamente livre, capaz de se expressar pela forma que melhor lhe convier, um poder que se funda sobre si mesmo, onímodo e incontrolável, justamente por ser anterior a toda normação e que abarca todos os demais poderes; um poder permanente e inalienável; um poder que depende apenas da sua eficácia. Em suma, podemos apontar três características básicas que se reconhecem ao poder constituinte originário. Ele é inicial, ilimitado (ou autônomo) e incondicionado.

12 BRASIL. Constituição Federal de 1988. Retirado do sítio de Internet <http://www.planalto.gov.br/ccivil_03/ constituicao/constituicao.htm>, com consulta em 24 de Janeiro de 2020.

Art. 211. A União, os Estados, o Distrito Federal e os Municípios organizarão em regime de colaboração seus sistemas de ensino.

§ 10 A União organizará o sistema federal de ensino e o dos Territórios, financiará as instituições de ensino públicas federais e exercerá, em matéria educacional, função redistributiva e supletiva, de forma a garantir equalização de oportunidades educacionais e padrão mínimo de qualidade do ensino mediante assistência técnica e financeira aos Estados, ao Distrito Federal e aos Municípios; (Redação dada pela Emenda Constitucional $n$ ㅇ 14, de 1996)

$\S 2$ 2o Os Municípios atuarão prioritariamente no ensino fundamental e na educação infantil. (Redação dada pela Emenda Constitucional no 14, de 1996)

§ 3으 Os Estados e o Distrito Federal atuarão prioritariamente no ensino fundamental e médio. (Incluído pela Emenda Constitucional no 14, de 1996)

Cf. ainda Lei 9.394, de 20 de Dezembro de 1996. Retirado do sítio de Internet <http://www.planalto.gov.br/ccivil_03/ leis/19394.htm>, com consulta em 20 de Janeiro de 2020.

13 MENDES, Gilmar Ferreira; COELHO, Inocêncio Mártires; BRANCO, Paulo Gustavo Gonet. Curso de Direito Constitucional. $4^{\circ}$ Ed, São Paulo-SP: Editora Saraiva, 2009.

32 | Revista do Programa de Pós-Graduação em Direito da UFBA, e-issn 2358-4777, v. 30, n. 01, p.25-39, Jan-Jun 2020 
É possível afirmar que há, para o ensino superior público no Brasil, uma limitação. Essa limitação faz com que esse serviço público - em verdade, uma concretização de um direito - não se consubstancie em direito humano, pois não carrega traços que caracterizam os direitos humanos propriamente ditos, como a universalidade, imperatividade e a generalidade. Se um direito não consegue alcanças e empunhar tais características, não se trata deles - humanos -, portanto, e sim outros tipos de direitos.

Não sendo um direito fundamental explícito e, também, não sendo um direito social, o ensino superior, por limitações dadas pelo texto constitucional - pois deve-se à capacidade de cada um-, submete-se a alguns limites que o faz não ser absoluto. Um deles, expresso no texto constitucional, liga-se à capacidade intelectual. Dessa, poderemos retirar algumas conclusões: tanto o ingresso, quanto o caminhar do curso propriamente dito e, por fim, a conclusão do mesmo, dependerá de aferimento intelectual para tanto. Se há provas para que se comprove capacidade e meritocracia intelectual para que se adentre e usufrua de um serviço público em específico - o ensino superior-, não estamos diante de um direito fundamental. Ao contrário dos ensinos fundamental ${ }^{14}$ e intermediário, a que tanto o Município quanto os Estados devem oferecer tantas vagas quanto sejam os pretendentes, pois não há escolhidos para um direito fundamental, o ensino superior não guarda tal generalidade por limitações igualmente constitucionais.

O constituinte escolheu uma limitação intelectual, que infraconstitucional e administrativamente consubstanciam-se em planejamentos junto às autarquias especiais universitárias - personalidade jurídica de Direito Público interno adotado pela ampla maioria das Universidades Públicas Federais no Brasil -, seja pelos antigos vestibulares, seja pelo atual ENEM - Exame Nacional do Ensino Médio - para que apenas aqueles que forem aprovados num concurso público para tanto, seja admitido a cursar o ensino superior junto às universidades públicas, de acordo com o curso escolhido, e alcançando uma nota tão alta quanto forem as maiores notas dentro do número de vagas destinadas ao curso.

\section{Cotas em Universidades Públicas}

As cotas nas universidades públicas foram previstas na Lei federal $12.711^{15}$, de 2012. Esta lei define que haverá vagas reservadas em universidades públicas para aqueles que cursaram o ensino básico e intermediário em escolas públicas, para aqueles que se declararem pardos, e ainda para aqueles que pertençam a um grupo econômico vulnerável específico. A lei afasta, assim, o acesso às universidades públicas federais daquilo que é previsto na literalidade do Artigo 208, inciso V, da Constituição Federal.

Se num primeiro momento não seria constitucional a adoção de cotas, sejam elas pela cor de pele, seja ela pela renda familiar ou, ainda, qualquer outro critério de distinção para vagas em estabelecimentos públicos de ensino para os níveis fundamentais e intermediários, na medida em que se consubstanciam, essas vagas, em direitos sociais constitucionais, e que por serviço público a educação, nesses níveis, não poderiam guardar limitação ou escolhidos, as mesmas cotas, para as vagas em universidades públicas, também encontram dificuldade em sua aplicabilidade. Não caberia, em nenhuma hipótese, a adoção de cotas para o ingresso em universidades públicas se não for atrelado, ainda, à capacidade intelectual do candidato à vaga, pois haveria flagrante inconstitucionalidade na lei 12.711 de 2012 se houvesse desrespeito à intelectualidade para o certame que definiria o ingresso às vagas do ensino superior público.

14 Cf. BRASIL. Constituição Federal. Artigo 30, VI. Retirado do sítio de Internet <http://www.planalto. gov.br/ccivil_03/constituicao/constituicao.htm>, com consulta em 20 de Janeiro de 2020.

15 BRASIL. Lei 12.711 de 2012 . Retirada do sítio de Internet <http://www.planalto.gov.br/ccivil_03/_ato20112014/2012/lei/l12711.htm>, com consulta em 25 de Janeiro de 2020.

33 | Revista do Programa de Pós-Graduação em Direito da UFBA, e-issn 2358-4777, v. 30, n. 01, p.25-39, Jan-Jun 2020 
É imperioso que haja compatibilidade entre as cotas previstas na lei ordinária e ainda o respeito à capacidade intelectual para o ingresso na universidade pública, sob pena de restar inconstitucional a norma infraconstitucional. A cota impõe, assim, um limite ao direito à isonomia constitucional, se aplicada entre iguais. Contudo, toma para si parâmetros existentes entre desiguais para buscar a própria igualdade. Agrupa, assim, conjuntos de pessoas que passarão a pertencer a blocos que guardem características que os farão, conjuntamente, ser tratados ordinária ou extraordinariamente, a depender do caso.

\section{Direito Internacional dos Direitos Humanos e Seus Reflexos no Brasil Acerca do Direito ao Ensino Superior Público}

Sendo certo que a literalidade do texto constitucional concede como direito social o ensino fundamental e o ensino médio, onde todos teriam direito à vaga em escolas públicas, sejam elas municipais, estaduais - distritais - ou federais nesses níveis, e que essa mesma literalidade concederia vagas em universidades públicas somente para aqueles que provarem-se aptos através de seleções que comprovassem sua capacidade intelectual para tanto, poderia o Direito Internacional e os tratados pertinentes ao tema trazer novos alcances para a formação acadêmica superior pública no Brasil?

A UNESCO - Organização das Nações Unidas para a Educação, Ciência e Cultura confeccionou um documento, durante sua Quadragésima Assembleia Geral, publicado em 3 de Setembro de 2019, intitulado Relatório em Construção para a Preparação da Convenção Global para o Reconhecimento da Qualificação no que tange ao Ensino Superior ${ }^{16}$. Neste documento, fica claro o posicionamento da ONU para que a educação de nível superior porte-se como direito humano no Direito Internacional, como parte da formação acadêmica continuada a que todo ser humano, desde criança, tem direito a escolher:

1. A educação de nível superior é reconhecida como uma parte integrante da Meta 4 do Desenvolvimento Sustentável - Educação 2030. A meta 4.3 cuida, para 2030, a assegurar a igualdade no acesso para todos os homens e mulheres a uma educação com preço justo e com qualidade técnica, vocacional e terciária, incluindo a Universidade. $\mathrm{O}$ reconhecimento das qualificações também está incluído nos indicadores estratégicos na Educação 2030.

2. Como a única agência das Nações Unidas com um mandato para a educação universitária, a UNESCO apoia que os Estados Membros no âmbito do reconhecimento de estudos, diplomas e graduações no nível universitário com uma visão a promover o direito à educação, a mobilidade acadêmica e o esforço internacional nesse sentido. Para isso, nas décadas de 1970 e 1980, UNESCO ajudou a desenvolver 6 instrumentos normativos, sendo cinco regionais e um inter-regional, para regular o reconhecimento das qualificações ao ensino superior. Em 2019, quatro desses instrumentos foram revistos, cobrindo as seguintes áreas geográficas: Europa e América do Norte (1997), Ásia e Pacífico (2011); África (2014); América Latina e Caribe (2019).

A mesma organização, reforçando seu pensamento sobre o ensino superior como parte natural e importante ao continuo desenvolvimento acadêmico e intelectual de toda criança e

16 UNESCO. Retirado do sítio de Internet <https://unesdoc.unesco.org/ark:/48223/pf0000370155>, com consulta em 25 de Janeiro de 2020. Em tradução nossa.

34 | Revista do Programa de Pós-Graduação em Direito da UFBA, e-issn 2358-4777, v. 30, n. 01, p.25-39, Jan-Jun 2020 
jovem, publicou um documento intitulado Seis maneiras para assegurar que a educação de nível superior não exclua ninguém ${ }^{17}$ :

Para fazer a educação uma catalizadora para a criação de sociedades sustentáveis, inovadoras e equânimes, os governos e as universidades têm que desenvolver políticas que façam das universidades e faculdades serviços com preços módicos e ainda inclusivas.

$[\ldots]$

Políticas de equidade em diferentes países miram diferentes grupos, e usam o alcance de estratégias para isso. Para criar oportunidades para estudantes com as mais variadas necessidades e expectativas, muitos países estão tentando expandir e diversificar a educação oferecendo e criando múltiplos caminhos possíveis entre o ensino médio e o ensino superior.

Técnicas legislativas e monitoramento por especialistas são a chave das ferramentas políticas nesse esforço. Requisições de admissão podem ser desenvolvidas para ajudar a alcançar a equidade visada. E trazendo a educação de nível superior para perto de potenciais beneficiários através da criação de novos institutos de nível superior em regiões menos desenvolvidas tem provado que é uma estratégia efetiva para uma maior equidade em muitos países.

Trata-se de recomendações para atuação conjunta dos poderes públicos e órgãos competentes dos países signatários da UNESCO sob o caminhar da educação de um país a fornecer, ao longo dos anos da formação de qualquer cidadão, uma formação acadêmica tão completa quanto for querida e necessária para que garanta-se uma instrução pessoal que o leve a independência financeira e social.

Heidi Gilchrist ${ }^{18}$ (2018, pg. 650-651), em artigo publicado junto à Revista de Direito da Universidade de Washington, nos traz conclusões que ligam, sim, o direito ao ensino superior aos direitos humanos. Ela lembra que a Convenção Internacional para os Direitos Culturais, Econômicos e Sociais, de 1966, junto à Organização das Nações Unidas, garante o direito de todos à educação, e que a educação em nível superior deve ser provida com equidade em seu acesso à todos, com base na capacidade, em todos os seus sentidos, e em particular pela progresso introdução da educação gratuita. Ela também alerta que, apesar de não ser um direito humano expresso e amplo, o ensino superior já é consagrado para os refugiados:

A Convenção dos Direitos da Criança é o tratado mais amplamente ratificado sobre o direito à educação, com 196 Estados ratificadores, e 1

17 UNESCO. Six ways to ensure higher education leaves no one behind. Em tradução nossa: Seis Maneiras para Assegurar que a Educação de Nível Superior não Exclua Ninguém. 2017. Livraria Digital da UNESCO UNESDOC - Digital Library. Retirado do sítio de Internet <https://unesdoc.unesco.org /ark:/48223/pf0000247862>, com consulta em 27 de Janeiro de 2020. Com tradução nossa:

Cf. ainda CROSIER, David; PARVEVA, Teodora. Le Processus de Bologne: son impact em Europe et dans le monde. UNESCO instituto international de planification de l’éducation. 2014. Paris.

18 Cf. GILCHRIST, Heidi. Higher Education as a Human Right. Vol. 17Washington University. New York. Global Studies Law Review, 2018. Disponível no sítio de Internet <https://brooklynworks.brooklaw.edu/cgi/ viewcontent.cgi?article=2011\&context=faculty $>$, com consulta em 27 de Janeiro de 2020. A autora traz uma posição diferente sobre o status jurídico do direito ao ensino superior, com todas as ressalvas entregues pelo ensino superior nos Estados Unidos, majoritariamente oferecido por instituições públicas, ao contrário do Brasil. Segundo a autora (2018, pg. 650), em tradução nossa. 
assinante mas não ratificador - os Estados Unidos. Assim, é uma importante fonte sobre o direito humano à educação em nível superior. O Artigo 28 da Convenção sobre os Direitos da Criança diz que os signatários devem fazer o ensino universitário acessível para todos com base na capacidade, em todos os seus sentidos, e devem fazer o ensino primário compulsório e disponível para todos.

[...]

Ao contrário de outros grupos, aos refugiados o direito à educação superior é extremamente limitado. A Convenção Relativa ao Status de Refugiados diz, em seu artigo 22(2), que Os Estados signatários acordam que o tratamento dispensado aos refugiados seja tão favorável quanto possivel, e, em qualquer evento, não menos favorável que aqueles dispensados aos estrangeiros nas mesmas circunstâncias, com respeito à educação elementar e, em particular, no que tange ao acesso aos estudos, o reconhecimento de certificados, diplomas e graduações advindas de escolas estrangeiras, o perdão de taxas e cobranças e ainda o reconhecimento de titulações escolares. ".

$\mathrm{Na}$ corrente regulamentação internacional sobre os refugiados, os Estados signatários do ACNUR devem tomar medidas para que a educação em nível superior seja igualmente acessível para todos e devem assegurar que seja provida sem discriminação, completa e imediatamente. No Direito Internacional, já há um direito à educação em geral e, ainda, à educação superior em específico. Educação precisa ser acessivel, acessivvel a todos sem discriminação, aceitável e adaptável. Olhando à quantidade de ratificações ao tratado, considerando a educação um direito humano sob o Direito Internacional, há um forte argumento que a educação é, certamente, um direito humano sob o direito internacional costumeiro. Um país com recursos, como os Estados Unidos, precisa reconhecer o ensino superior como um direito humano $e$ observar de perto as barreiras da acessibilidade para aqueles que são desfavorecidos ou que pertencem aos grupos hipossuficientes.

Quanto às pessoas portadoras de deficiências, no Brasil, observando que apenas dois tratados internacionais sobre direitos humanos pertinentes ao tema (pessoas com necessidades especiais) foram recepcionados pelo Ordenamento Brasileiro seguindo os parâmetros procedimentais previstos no parágrafo $3^{\circ}$ do Artigo $5^{\circ}$ do texto constitucional, vê-se que 0 direito ao acesso ao ensino universitário superior no Brasil é garantido para elas, conforme o Decreto $6.949^{19}$, de 25 de Agosto de 2009, que promulgou a Convenção Internacional sobre os

19 BRASIL. Decreto 6.949 de 2009. Retirado do sítio de Internet <http://www.planalto.gov.br/ccivil_03/ _ato2007-2010/2009/decreto/d6949.htm>, com consulta em 25 de Janeiro de 2020:

Artigo 24

Educação

5.Os Estados Partes assegurarão que as pessoas com deficiência possam ter acesso ao ensino superior em geral, treinamento profissional de acordo com sua vocação, educação para adultos e formação continuada, sem discriminação e em igualdade de condições. Para tanto, os Estados Partes assegurarão a provisão de adaptações razoáveis para pessoas com deficiência. 
Direitos das Pessoas com Deficiência e seu Protocolo Facultativo, assinados em Nova York, em 30 de março de 2007. Assim, o direito ao acesso aos níveis superiores de ensino público por pessoas com deficiência é uma regra geral para essa categoria de estudantes. Contudo, é uma exceção com status constitucional à restrição ao acesso aos níveis mais altos do ensino no Brasil, visto que não houve ainda tratados acerca do ensino superior como um passo para a concretização de direitos humanos, que necessitam, também, de generalidade, no Brasil, e que aportem todos os cidadãos.

\section{Conclusão}

O ensino superior no Brasil não é para todos. Pelo menos até o presente momento. Uma afirmação dura, mas positivamente consagrada na Constituição Federal. O ensino básico e o ensino intermediário são direitos sociais exigíveis do Poder Público competente para tal, pois, se não disponíveis a aqueles que queiram estudar, mostra-se violado um direito social constitucional, cuja obrigação é encargo do Poder Público, e cuja organização, dada pela própria Constituição Federal e pela Lei de Diretrizes e Bases da Educação Nacional, dirigiu-se que cada pessoa jurídica componente da Federação seria encarregada por um nível de escolarização. Assim, os Municípios, de um lado, e os Estados, de outro, podem ser compelidos judicialmente a fornecer vagas escolares para o ensino público fundamental e intermediário.

O ensino público de nível superior, contudo, é acessível apenas para aqueles que demonstrem capacidade intelectual para tanto, com exceção, hoje, para aqueles portadores de deficiência e ainda para aqueles que são refugiados no Brasil-com as ressalvas intelectuais que injustamente classificam genericamente os refugiados como hipossuficientes acadêmicos, haja visto, por exemplo, a quantidade de doutores venezuelanos que migraram de modo hipossuficinte para outros países da América. O modelo escolhido administrativa e legalmente no Brasil, majoritariamente, é um exame unificado, aplicado pelo INEP, ou ainda, vestibulares adotados pelas Universidades Públicas federais que assim decidam. Logicamente, trata-se de um quadro para o âmbito federal, ao passo que ainda temos universidades estaduais ou distritais que prestem educação pública de nível superior, e que também são obrigadas a abandonar a universalidade do oferecimento do ensino para também adotarem a meritocracia e a avaliação acadêmica, tanto para o ingresso, quanto para o cumprimento do curso e sua conclusão.

Afora o estudo das cotas, sejam elas pela pigmentação da pele, pela formação em escolas públicas secundaristas ou ainda por classificações econômicas, algo que poderia ser dirigido por uma política pública, o acesso ao ensino público superior não poderá ser garantido pelo direito constitucional ao ensino - que abrange o ensino fundamental e o intermediário. Se as cotas são embasadas na isonomia constitucional, onde busca-se tratar os diferentes de modo diferente, na medida inversa de suas diferenças, possibilitando que pessoas que portem traços diferenciadores também possam usufruir de condições de seleção diferenciadas, a seleção para as universidades públicas também possuem, igualmente, natureza constitucional, permitindo o aporte acadêmico e intelectual como único modo de seleção, e cuja infringência poderia, sim, violar a própria meritocracia e a isonomia.

O caminhar da construção do ensino público passa, necessariamente, ao alcance de todos aos mais altos níveis de ensino. Pensar que o aprendizado é algo a que todo ser humano deve buscar até o fim dos seus dias seria uma conclusão bastante invasiva, singular e romântica. Cada um possui sua autonomia a buscar as escolhas que desenha para sua própria vida, seja alcançar os mais altos níveis de escolaridade e pesquisa científica; seja abandoná-la em quaisquer pontos de seu desenvolvimento. Contudo, o direito à educação superior ainda não é constitucionalmente garantido como fundamental, nem muito menos um direito social. Poderá 
um dia ser, por emendas constitucionais ou, ainda, por interações positivas nesse sentido através de tratados internacionais de direitos humanos sobre o tema.

A formação universitária para jovens, ao redor do mundo, é uma preocupação junto à UNESCO, e referida posição junto ao órgão da ONU para a infância e juventude, que posiciona-se sobre o ensino universitário como um direito, e ainda como uma obrigação estatal, vai, sim, de encontro a aquilo dito pela Constituição Federal. Construindo-se o ensino superior, internacionalmente, como um direito humano, majoritariamente fundamentado como um dos meios ao contínuo desenvolvimento da infância e da juventude, restaria esperar que a República Federativa do Brasil alinhe-se a esse pensamento, por meio de tratados internacionais sobre direitos humanos, a trazer disposições a garantir, só assim, mais esse direito à juventude brasileira.

Por fim, ainda restaria a vexatio questio frente a quantidade a ser ofertada e a qualidade de excelência, essa última determinada pela Constituição. Observemos que o Artigo 37 da Constituição Federal, supra, impõe que não poderá haver prestação de um serviço público sem alcance de eficiência. Contudo, a própria Constituição Federal excepciona-se, sobre o ensino público superior, quando assevera, de um lado, que qualquer ensino público deve, sim, obediência à eficiência a prestação desse serviço, conforme o artigo 37; contudo, sobre o ensino superior, seu acesso se dará apenas, e somente apenas, de acordo com a capacidade de cada um, sem detalhes sobre percentagens, algo a guardar-se para a legislação infraconstitucional, mas que garante a ausência de universalidade ao ensino superior público no Brasil.

\section{Referências}

BULOS, Uadi Lammêgo. Curso de Direito Constitucional. 9a Ed, São Paulo: Editora Saraiva, 2015. CARVALHO, Matheus. Manual de Direito Administrativo. 2a Ed, São Paulo-SP: Editora Jus Podivm, 2015.

CROSIER, David; PARVEVA, Teodora. Le Processus de Bologne: son impact em Europe et dans le monde. UNESCO instituto international de planification de l'éducation. Paris: 2014.

FERNANDES, Bernardo Gonçalves. Curso de Direito Constitucional. 9a Edição, São Paulo-SP: Editora Jus Podivm, 2017.

GILCHRIST, Heidi. Higher Education as a Human Right. Washington University. Global Studies Law Review. Vol. 17, Washington: 2018. Disponível no sítio de Internet <https://brooklynworks. brooklaw.edu/cgi/viewcontent.cgi?article=2011\&context=faculty>, com consulta em 27 de Janeiro de 2020.

GURGEL. Yara Maria Pereira. Conteúdo Normativo da Dignidade da Pessoa Humana e suas Implicações Jurídicas na Realização dos Direitos Fundamentais. Tese de Pós-Doutoramento em Direito e Ciências Jurídicas. Lisboa. 2018.

MENDES, Gilmar Ferreira; COELHO, Inocêncio Mártires; BRANCO, Paulo Gustavo Gonet. Curso de Direito Constitucional. 4a Ed, São Paulo-SP: Editora Saraiva, 2009.

MOREIRA, Thiago Oliveira. A Concretização dos Direitos Humanos dos Migrantes pela Jurisdição Brasileira. 1a Ed, Curitiba - PR: Instituto Memória Editora. Centro de Estudos da Contemporaneidade, 2019.

NOVAIS, Jorge Reis. Direitos Fundamentais: Trunfos Contra a Maioria. Coimbra: Coimbra Editora, 2006.

PIETRO, Maria Sylvia Zanella di. Direito Administrativo. Vigésima Sétima Edição, São Paulo-SP: Editora Atlas S.A, 2014.

Posições de Organismos Internacionais: 
UNESCO. Six ways to ensure higher education leaves no one behind. Em tradução nossa: Seis Maneiras para Assegurar que a Educação de Nível Superior não Exclua Ninguém. 2017. Livraria Digital da UNESCO - UNESDOC - Digital Library. Retirado do sítio de Internet <https://unesdoc.unesco.org /ark:/48223/pf0000247862>

Legislação:

BRASIL. Retirado do sítio de Internet <http://www.planalto.gov.br> 